\title{
Long-term combined exercises enhance sweet taste sensitivity and reduce carbohydrate intake in patients with type 2 diabetes mellitus
}

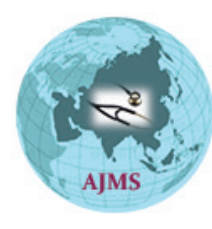

\author{
Dinithi Vidanage ${ }^{1}$, Sudharshani Wasalathanthri ${ }^{2}$, Priyadarshika Hettiarachchi ${ }^{3}$ \\ ${ }^{1}$ Lecturer, Department of Nursing and Midwifery, Faculty of Allied Health Sciences, General Sir John Kotelawala \\ Defence University, Rathmalana, Sri Lanka, ${ }^{2}$ Professor, Department of Physiology, Faculty of Medicine, University of \\ Colombo, Kynsey Road, Colombo 08, Sri Lanka, ${ }^{3}$ Professor, Department of Physiology, Faculty of Medical Sciences, \\ University of Sri Jayewardenepura, Nugegoda, Sri Lanka
}

Background: The link between sweet taste perception and carbohydrate intake in diabetics who perform regular combined exercises has not been explored. Aims and Objectives: This study aimed at determining the impact of combined exercises on taste perception for sucrose and carbohydrate intake in patients with type 2 diabetes mellitus. Materials and Methods: A clinical trial was conducted with 225 patients with T2DM, aged 35-60 years assigned randomly into three groups; aerobic, combined, and a control group. Outcomes of the aerobic group were not reported. Combined group performed brisk walking 4-5 days/week and resistance exercises 2-3 days/week for 6 months. Supra-threshold intensity ratings, preference for sucrose, and carbohydrate intake assessed at baseline, at 3 and 6 months were measured using "general Labeled Magnitude Scale," "Monell 2-series-forced choice method," and a 3-day diet diary, respectively. Results: Ratings for the highest (combined vs. control: $+3.15 \pm 0.57$ vs. $-7.96 \pm 0.40 \mathrm{~mol} / \mathrm{L}, \mathrm{P}=0.022$ ) and the second-highest sucrose concentrations (combined vs. control: $+7.79 \pm 4.49$ vs. $-8.98 \pm 0.99 \mathrm{~mol} / \mathrm{L}, \mathrm{P}=0.003$ ) in the combined group were significantly higher with significant time $\times$ group interaction (2.02M: $P=0.002,0.64 \mathrm{M}: \mathrm{P}=0.003)$. Preference for sucrose was lower in the combined group (combined vs. control: $-0.08 \pm 0.14 \mathrm{vs}$. $+0.01 \pm 0.03 \mathrm{~mol} / \mathrm{L}, \mathrm{P}=0.002$ ), and the time $\times$ group interaction was not significant. Carbohydrate intake (combined vs. control: $-46.97 \pm 21.60$ vs. $-6.30 \pm 9.36 \mathrm{~g}, \mathrm{P}=0.001$ ) and $\mathrm{HbA} 1 \mathrm{c}$ level (combined vs. control: $-0.66 \pm 1.81$ vs. $+0.33 \pm 1.84 \%, P=0.008$ ) were reduced in the combined group, and taste sensitivity significantly predicted the carbohydrate intake with combined exercises $\left(R^{2}=0.64, P=0.01\right)$. Conclusion: Regular combined exercises increase sweet taste sensitivity for higher concentrations of sucrose. Taste sensitivity, not the preference determines the carbohydrate intake in exercising diabetics.

Key words: Exercise; Food intake; Taste sensitivity

\section{INTRODUCTION}

Taste is an important sense which drives food choices in humans. ${ }^{1}$ Of all key taste qualities, the sweet taste is unique since the sweet taste receptor TAS1R2 is known to be associated with carbohydrate intake in humans. ${ }^{2}$ Although it is evident that patients with type 2 diabetes mellitus (T2DM) have impaired taste sensation, the sweet taste
Access this article online

\section{Website:}

http://nepjol.info/index.php/AJMS

DOI: 10.3126/ajms.v13i2.40915

E-ISSN: 2091-0576

P-ISSN: 2467-9100

Copyright (c) 2022 Asian Journal of Medical Sciences

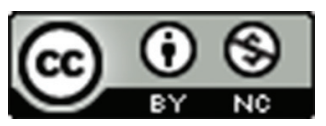

This work is licensed under a Creative Commons Attribution-NonCommercial 4.0 International License. 
amounts of sweets leading to hyperglycemia or vice versa. ${ }^{6}$ Further, it is reported that sugar triggers food-seeking behavior through acting on brain centers. ${ }^{7}$ Thus, it is imperative to break this vicious cycle and improve the taste sensitivity in diabetics. In addition to activities of the daily routine, performing structured physical exercises are no more optional and experiments on healthy adults have shown that physical activity plays a vital role in improving taste sensitivity. ${ }^{8,9}$ Engaging in combined exercises (combination of aerobic and resistance exercises) for at least 2 days/week is superior to aerobic or resistance alone, since combined exercises have a proven value in improving glycemic response. ${ }^{10}$

A negative correlation was observed between sweet taste sensitivity and carbohydrate (glucose, fructose) intake in healthy adults following aerobic exercises. ${ }^{11}$ However, most studies have not used the typical sweet which is sucrose, in diabetics. Thus, the present prospective study aimed at determining the impact of long-term combined exercises on taste perception, that is, taste sensitivity and preference for sucrose and its association with carbohydrate intake in patients with T2DM.

\section{Aims and objectives}

The aim of this study was to determine the impact of combined exercises on taste perception for sucrose and its association with carbohydrate intake in patients with T2DM.

\section{MATERIALS AND METHODS}

\section{Trial design and setting}

This is a randomized controlled trial (SLCTR/2015/029) conducted at the Department of Physiology, University of Sri Jayewardenepura, Sri Lanka. Trial registration: (SLCTR/2015/029, https://slctr.lk/trials/slctr-2015-029).

\section{Participants}

Patients with T2DM for more than 5 years, aged 35-60 years with glycated hemoglobin (HbA1c) between $6.6 \%$ and $9.9 \%$, who were willing to perform regular exercises and maintain a 3-day diet diary were recruited. Those with diseases of the oral cavity, smokers, betel chewers, and regular alcohol consumers were excluded. ${ }^{12}$ Participants with ischemic heart disease, uncontrolled hypertension, psychiatric illnesses, physical and neurological disorders that affect exercises were also excluded.

\section{Selection of participants}

Patients attending to the Family Practice Centre, University of Sri Jayewardenepura, Sri Lanka were enrolled after obtaining written consent. A sample of 225 patients was assigned into three groups (aerobic, combined and a control group) using a random number table (1:1 allocation ratio). A randomly picked number was matched with the patient's serial number. Thus, the first, second and third matched numbers were assigned to the aerobic, combined and the control groups, respectively. All groups were matched for age, gender and body mass index to minimize confounders. Blinding was not done. A pilot study was conducted on 10 participants who fulfilled similar inclusion and exclusion criteria.

\section{Outcomes}

The primary outcome measures were the change in taste perception for sucrose (i.e., supra-threshold intensity ratings and preference) and carbohydrate intake in the combined group from baseline to 3 and 6 months compared to the control group. The association between taste perception and carbohydrate intake at 3 and 6 months; and HbA1c levels at 6 months in combined and control groups were the secondary outcomes. The outcomes in the aerobic group were not reported in this manuscript.

\section{Data collection}

Baseline characteristics of participants were recorded at the recruitment. Taste perception and food intake were assessed at baseline, at 3 and 6 months, in batches of 5-6 participants/day. The glycemic control (HbA1c) was assessed at baseline and 6 months using high liquid performance chromatography method. The participants were instructed to abstain from food and beverages from $10 \mathrm{pm}$ the previous day and have $6-8 \mathrm{~h}$ of sleep. Only morning tea/coffee was allowed. On arrival at the study setting, the participants were served a standard breakfast comprising of a banana, 3 slices of brown bread with margarine, followed by a glass of water. Five milliliters $(5 \mathrm{~mL})$ of blood were drawn under strict aseptic measures to determine HbA1c levels.

\section{Combined exercise intervention}

A graded home-based exercise protocol ${ }^{13}$ was introduced to the participants in the combined group. They were instructed to perform brisk walking for a minimum of $150 \mathrm{~min} /$ week spanning over $4-5$ days $(30 \mathrm{~min} /$ day). To ensure the accurate assessment of the exercises, each participant was provided with a "pedometer" which provides step count, the distance of walk, and the number of calories burnt during each walking session. Participants were instructed to use stretch bands in performing resistance exercises for at least 2 days/week. Adherence to the exercise protocol was ensured by telephone reminders in the $2^{\text {nd }}$ week of each month.

\section{Assessment of taste perception}

Supra-threshold for sucrose was assessed using the general Labeled Magnitude Scale (gLMS). ${ }^{14}$ Serial concentrations 
of sucrose solutions were prepared based on $1 / 2 \log$ steps $\left(3.16\right.$-fold $\left./ 10^{0.25}\right)$. The mean recognition threshold obtained in a previous study was used as the barely detectable level. ${ }^{5}$ Six cups $(5 \mathrm{~mL}$ each) of sucrose solutions $(2.02 \mathrm{M}, 0.64 \mathrm{M}$, $0.2 \mathrm{M}, 0.064 \mathrm{M}, 0.0202 \mathrm{M}, 0.0064 \mathrm{M})$ were presented to each participant in a random order maintaining a gap of 1 minute. Participants were asked to taste each sample for $5 \mathrm{~s}$ before spitting it out and rate the perceived intensity on a gLMS paper scale. Supra-threshold intensity rating was averaged after repeating the procedure for 3 times. ${ }^{15}$

Taste preference was tested by Monel 2-series forced-choice method using pairs of sucrose solutions, $5 \mathrm{~mL}$ each. The procedure was repeated twice consecutively using serial concentrations of sucrose (i.e., 0.09M, 0.18M, 0.36M, $0.72 \mathrm{M}, 1.08 \mathrm{M}) .{ }^{16}$ In series 1 , concentrations of the middle range were presented (avoiding the highest and the lowest concentrations) in pairs, with the weaker concentration given first. The participants tested each solution in the pair for $5 \mathrm{~s}$ before choosing the solution they liked. This procedure was continued with varying pairs of different concentrations until the participant chose the solution with the same concentration twice consecutively, which was considered as the preferred solution in series 1 . In series 2 which commenced in a gap of $3 \mathrm{~min}$, the stronger concentration of the pair was presented first and the same procedure was repeated. The geometric mean of the 2 sucrose concentrations chosen in series 1 and 2 was considered as the preferred concentration of sucrose for a participant.

\section{Assessment of food intake}

A 3-day diet diary was used to assess the regular dietary behaviors of the participants. Participants were allowed to consume their routine meals throughout the study period. They were instructed to record their meals on 2-week days and 1-day on the weekend. Dietary records were collected by the principal investigator at baseline, at 3, and 6 months. The total calorie and macronutrient intakes were determined using a software (EBISCO Nutrisurvey 2007) which has been adopted to routine Sri Lankan food. ${ }^{17}$

\section{Statistical analysis}

All data were analyzed using SPSS software version 23.0. Descriptive data of participants were reported as numbers and percentages or means and standard deviations $( \pm S D)$. Absolute ratings obtained for taste perception for sucrose and carbohydrate intake at baseline, at 3 and 6 months between the intervention and control groups were compared by independent sample t-test. Mean differences $(\Delta \pm \mathrm{SD})$ of taste perception and carbohydrate intake obtained by deducting the baseline values from the 3 -and 6-month values of the combined group were compared with that of the control group by independent sample t-test. Mean differences $(\Delta \pm \mathrm{SD})$ of HbA1c (between baseline and 6 months) were also compared by independent sample t-test. Two-way repeated-measures ANOVA, (i.e., time [within-subject factor] and group [between-subject factor]) was performed to assess the impact of two conditions (intervention/control) on taste perception for sucrose in 3 time points (i.e., baseline, 3 , and 6 months). Association between taste perception and carbohydrate intake was assessed using Multiple Linear Regression.

\section{Ethical considerations}

The study protocol was approved by the Ethics Review Committee (ERC approval no. 10/18) of the Faculty of Medical Sciences, University of Sri Jayewardenepura, Sri Lanka.

\section{RESULTS}

Sixty-four participants in the combined group and 63 participants in the control group completed the study with a response rate of $86 \%(n=127)$ at 3 months. Seventy six percent of the participants $(n=115)$ remained until completion of the study at 6 months (i.e., combined $=55$, control=60). Figure 1 shows the outcome of the recruited participants.

Baseline sociodemographic, anthropometric and clinical characteristics of participants in the combined and control groups were similar at the recruitment (Table 1).

The impact of exercises on taste sensitivity for sucrose No significant difference was found in the supra-threshold intensity ratings for any of the sucrose solutions between the combined and the control group at baseline (data not shown). Rating for the highest concentration (2.02M) of sucrose given by the combined group was significantly higher compared to that of the control group at 3 months. At 6 months, the supra-threshold intensity ratings of the combined group for all sucrose solutions displayed an increasing trend compared to controls and were significantly higher for the highest $(2.02 \mathrm{M})$ and the second-highest concentration $(0.64 \mathrm{M})$ compared to controls (Table 2$)$.

Two-way repeated measures ANOVA showed a significant time $\times$ group interaction (Wilk's Lambda) $(\mathrm{F}[2,112]=6.61$, $\mathrm{P}=0.002$, partial eta squared $=0.106)$ in supra-threshold intensity ratings for the highest sucrose solution (2.02M) as well as for the second-highest concentration (0.64M), (Pillai's Trace $)(\mathrm{F}[2,112]=6.18, \mathrm{P}=0.003$, partial eta squared $=0.099)$ across 3 time points in the combined group.

The impact of exercises on preference for sucrose No significant difference in the preference for sucrose between the combined and the control group was noted 


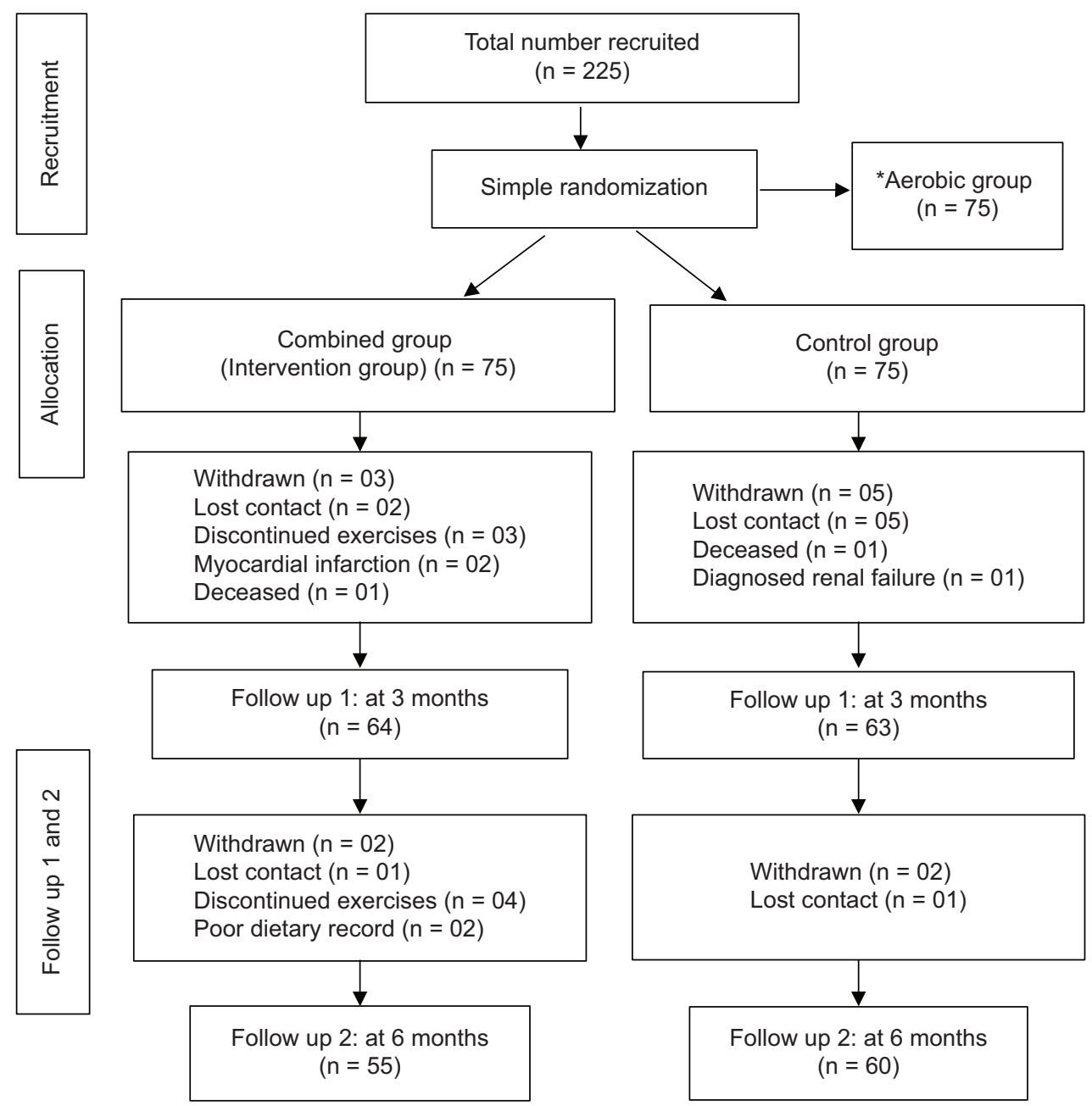

Figure 1: Flow diagram showing the outcome of recruited participants as per CONSORT guidelines 2010. *Outcomes of the aerobic group were not reported

at baseline (data not shown). The preference for sucrose was significantly reduced following combined exercises at 6 months compared to controls (Table 2). Two-way repeated-measures ANOVA revealed that there was no significant effect of time $\times$ group interaction $(F$ $[2,112]=7.98, \mathrm{P}=0.399$, partial eta squared $=0.125)$ on preference for sucrose over the 3 time points.

\section{Association between taste perception and carbohydrate intake}

At the end of follow-ups; the combined group exhibited a significant reduction in carbohydrate intake compared to controls at $3(\mathrm{P}=0.05)$ and 6 months $(\mathrm{P}=0.001)$ (Table 2). Multiple linear regression analysis revealed that each $1 \mathrm{~mm}$ increase in supra-threshold intensity ratings for sucrose reduces the carbohydrate intake by $5.2 \mathrm{~g}$ at 6 months in the combined group $\left(\mathrm{F}[8,17]=3.817, \mathrm{R}^{2}=0.64, \mathrm{P}=0.01\right)$. No significant association was observed at 3 months in both groups.

\section{DISCUSSION}

In this study, the impact of combined exercises on taste perception for sucrose and the association between taste perception and carbohydrate intake was determined in patients with T2DM engaging in combined exercises over a period of 6 months. Over the previous decades, extensive attention has been received particularly for sweet taste thresholds in diabetics. Yet investigations exploring the link between sweet taste perception with carbohydrate intake in patients with T2DM who perform long-term combined exercises are lacking to date. In the present study, the impact of combined exercises on sweet taste sensitivity was significantly higher for higher sucrose concentrations compared to controls. Previous studies support our observation although these findings are limited to healthy adults performing aerobic exercises for a maximum duration of 12 weeks. 


\begin{tabular}{|c|c|c|c|}
\hline Variable & Combined group $(n=75)$ & Control group $(n=75)$ & P-value \\
\hline Age (years) (mean $\pm S D)$ & $53.36 \pm 4.94$ & $54.70 \pm 5.41$ & 0.104 \\
\hline \multicolumn{4}{|l|}{ Gender, n (\%) } \\
\hline Male & $39(52 \%)$ & $32(42.6 \%)$ & \multirow[t]{2}{*}{0.327} \\
\hline Female & $36(48 \%)$ & $43(57.4 \%)$ & \\
\hline \multicolumn{4}{|l|}{ Education level, n (\%) } \\
\hline No education & 0 & 0 & \multirow[t]{6}{*}{0.636} \\
\hline Grade $1-5$ & 0 & $01(1.3 \%)$ & \\
\hline Grade 6-10 & $15(20 \%)$ & $16(21.3 \%)$ & \\
\hline Up to ordinary level & $36(48 \%)$ & $39(52 \%)$ & \\
\hline Up to advanced level & $19(25.3 \%)$ & $17(22.7 \%)$ & \\
\hline Tertiary education & $05(6.7 \%)$ & $02(2.7 \%)$ & \\
\hline \multicolumn{4}{|l|}{ Civil status, $\mathrm{n}(\%)$} \\
\hline Married & $69(92.0 \%)$ & $66(88 \%)$ & \multirow[t]{2}{*}{0.588} \\
\hline Unmarried & $06(8.0 \%)$ & $09(12 \%)$ & \\
\hline \multicolumn{4}{|l|}{ Mode of treatment, $\mathrm{n}(\%)$} \\
\hline On their own & $07(9.3 \%)$ & $13(17.3 \%)$ & \multirow[t]{3}{*}{0.595} \\
\hline Regular clinic visits & $28(37.3 \%)$ & $49(65.4 \%)$ & \\
\hline Private doctor & $40(53.4 \%)$ & $13(17.3 \%)$ & \\
\hline \multicolumn{4}{|l|}{ Use of oral hypoglycemics, n (\%) } \\
\hline No use & $11(14.6 \%)$ & $07(9.3 \%)$ & \multirow[t]{3}{*}{0.081} \\
\hline Metformin & $60(80.0 \%)$ & $56(74.7 \%)$ & \\
\hline Other hypoglycemics & $04(5.4 \%)$ & $12(16 \%)$ & \\
\hline Duration of T2DM (years) (mean \pm SD) & $7.75 \pm 2.56$ & $9.6 \pm 6.35$ & 0.068 \\
\hline \multicolumn{4}{|l|}{ Family history of T2DM, n (\%) } \\
\hline Yes & $40(53.4 \%)$ & $43(57.3 \%)$ & \multirow[t]{2}{*}{0.625} \\
\hline No & $35(46.6 \%)$ & $32(42.7 \%)$ & \\
\hline BMI $\left(\mathrm{kg} / \mathrm{m}^{2}\right)($ mean $\pm \mathrm{SD})$ & $25.74 \pm 3.50$ & $25.28 \pm 3.03$ & 0.394 \\
\hline $\mathrm{HbA} 1 \mathrm{c}(\%)($ mean $\pm \mathrm{SD})$ & $7.69 \pm 1.48$ & $7.94 \pm 1.14$ & 0.249 \\
\hline
\end{tabular}

\begin{tabular}{|c|c|c|c|c|c|c|}
\hline \multirow[t]{2}{*}{ Outcome variables } & \multicolumn{3}{|c|}{$\begin{array}{c}\text { Mean differences } \pm \text { SD between } 0 \text { and } 3 \\
\text { months }^{*}\end{array}$} & \multicolumn{3}{|c|}{ Mean differences $\pm S D$ between 0 and 6 months } \\
\hline & $\begin{array}{c}\text { Combined } \\
(n=64)\end{array}$ & $\begin{array}{c}\text { Control } \\
(n=63)\end{array}$ & $P$ value & $\begin{array}{l}\text { Combined } \\
(n=55)\end{array}$ & $\begin{array}{l}\text { Control } \\
(n=60)\end{array}$ & $P$ value \\
\hline \multicolumn{7}{|l|}{$\begin{array}{l}\text { Supra-threshold } \\
\text { intensity ratings } \\
\text { for sucrose } \\
\text { concentrations (mol/L) }\end{array}$} \\
\hline 2.02 & $+6.63 \pm 2.50$ & $-4.01 \pm 1.79$ & $0.020^{*}$ & $+3.15 \pm 0.57$ & $-7.96 \pm 0.40$ & $0.022^{*}$ \\
\hline 0.64 & $+7.26 \pm 2.76$ & $+2.72 \pm 8.68$ & 0.276 & $+7.79 \pm 4.49$ & $-8.98 \pm 0.99$ & $0.003^{*}$ \\
\hline 0.202 & $-1.20 \pm 1.94$ & $-1.44 \pm 4.15$ & 0.947 & $+0.93 \pm 1.59$ & $-0.16 \pm 5.01$ & 0.815 \\
\hline 0.064 & $-1.00 \pm 2.15$ & $-1.66 \pm 5.26$ & 0.861 & $+2.16 \pm 2.07$ & $-1.69 \pm 4.28$ & 0.148 \\
\hline 0.0202 & $+0.64 \pm 1.47$ & $+1.14 \pm 0.18$ & 0.904 & $+0.89 \pm 2.01$ & $-1.20 \pm 2.57$ & 0.141 \\
\hline 0.0064 & $-0.08 \pm 1.02$ & $-0.16 \pm 1.27$ & 0.885 & $+0.17 \pm 1.75$ & $-0.34 \pm 2.46$ & 0.633 \\
\hline $\begin{array}{l}\text { Preference for } \\
\text { sucrose (mol/L) }\end{array}$ & $-0.03 \pm 0.12$ & $+0.01 \pm 0.09$ & 0.726 & $-0.08 \pm 0.14$ & $+0.01 \pm 0.03$ & $0.002^{*}$ \\
\hline $\begin{array}{l}\text { Carbohydrate intake/ } \\
\text { day }(\mathrm{g})\end{array}$ & $-29.77 \pm 14.73$ & $+14.96 \pm 2.73$ & $0.050^{*}$ & $-46.97 \pm 21.60$ & $-6.30 \pm 9.36$ & $0.001^{*}$ \\
\hline $\mathrm{HbA} 1 \mathrm{c} \%$ & - & - & - & $-0.66 \pm 1.81$ & $+0.33 \pm 1.84$ & $0.008^{*}$ \\
\hline
\end{tabular}

* Level of significance $P<0.05$, values are expressed as mean \pm SD (Independent sample t-test). "Baseline value was deducted from the 3 month value (o and 3 months). "Baseline value was deducted from the 6 month value (o and 6 months)

An increased sweet taste sensitivity in physically active healthy adults compared to inactive individuals was reported in a recent systematic review. ${ }^{11}$ Umabiki et al., ${ }^{9}$ observed an increase in the sweet taste sensitivity (recognition threshold) after 12 weeks of aerobic exercises. Moreover, ratings for sucrose (supra-threshold) were higher in active men (who perform $>4$ exercise sessions/week) compared to inactive men. ${ }^{8}$ In this context, we postulate that taste sensitivity for sucrose improves in diabetics who perform regular combined exercises. 
Although hormone analysis was beyond the scope of our study, increased ratings for sucrose may be attributed to hormonal changes, as patients with T2DM have shown increased levels of glucagon-like peptide-1 (GLP-1) and reduced levels of leptin following 12-weeks of aerobic exercises. ${ }^{18}$ Moreover, GLP-1 receptors have been identified in taste buds in mammals and GLP-1 signaling plays an important role in enhancing sweet taste sensitivity. ${ }^{19}$

Preference for sucrose was reduced at 6 months, but the impact of combined exercises altering preference for sucrose was not evident in the present study. In agreeable to our study, change in liking for sucrose was not observed in active healthy men compared to inactive men. ${ }^{8}$ In contrast, Crystal et al., ${ }^{20}$ emphasized that the preference for sucrose was lower in female swimmers compared to females who exercise $<3 \mathrm{~h} /$ week. Similarly, habitual exercise was associated with a lower likelihood to choose sweet food in healthy individuals. ${ }^{21}$ The findings may differ since the present study participants were diabetics and previous study observations were based on healthy adults.

Multiple linear regression analysis after controlling for age, gender and $\mathrm{HbA} 1 \mathrm{c}$ revealed a strong negative correlation between taste sensitivity and carbohydrate intake. This finding is supported by several recent observations. ${ }^{1,22}$ A recent study showed that the recognition threshold for sucrose was significantly associated with sweets and desserts intake in healthy adults. ${ }^{22}$ According to Low et al., ${ }^{23}$ intensity ratings are more appropriate in assessing the associations with energy intake compared to detection and recognition thresholds. Low et al., ${ }^{23}$ observed that the intensity ratings for the strongest sucrose concentration $(0.4 \mathrm{M})$ were inversely correlated with energy intake in healthy individuals. In contrast, fact that carbohydrate intake in the present study was correlated with intensity rating for a higher concentration $(2.02 \mathrm{M})$ maybe because our participants were diabetics whereas the previous study participants were healthy adults. In agreeable to our study, a significant negative correlation was observed between supra-threshold intensity for glucose and carbohydrate intake in healthy women. ${ }^{24}$ Overall, the current findings indicate an association between supra-threshold intensity for higher sucrose concentrations and carbohydrate intake.

In the present study, no significant association was observed between preference for sucrose and intake of carbohydrates. Similarly, a group of healthy Asian females also did not show any significant association between preference for sucrose and carbohydrate intake..$^{25}$ Thus, we conclude that preference for sucrose provides a limited utility in determining the carbohydrate intake in diabetics.
In the present study, glycemic response was improved in the combined group. Although it is well established that glycemic response improves with combined exercises, ${ }^{10}$ improvement of taste sensitivity may have contributed to achieve the glycemic control by reducing carbohydrate intake.

\section{CONCLUSION}

Regular combined exercises improve taste sensitivity for sucrose particularly in higher concentrations and tend to reduce the carbohydrate intake in diabetics. Taste sensitivity, but not the taste preference predicts carbohydrate intake in diabetics who perform regular combined exercises. Combined exercises promote a reduction in carbohydrate intake through increasing sweet taste sensitivity and foster glycemic control.

\section{ACKNOWLEDGMENTS}

The authors are grateful to the participants, who made this study possible. The Research Council of University of Sri Jayewardenepura, is acknowledged for funding the study (ASP/01/RE/MED/2017/31).

\section{REFERENCES}

1. Tan SY and Tucker RM. Sweet taste as a predictor of dietary intake: A systematic review. Nutrients. 2019;11(1):94. https://doi.org/10.3390/nu11010094

2. Ramos-Lopez O, Panduro A, Martinez-Lopez E and Roman S. Sweet taste receptor TAS1R2 polymorphism (Val191Val) is associated with a higher carbohydrate intake and hypertriglyceridemia among the population of West Mexico. Nutrients. 2016;8(2):101. https://doi.org/10.3390/nu8020101

3. Tepper BJ, Hartfiel LM and Schneider SH. Sweet taste and diet in type II diabetes. Physiol Behav. 1996;60(1):13-18. https://doi.org/10.1016/0031-9384(95)02242-2

4. Bartoshuk LM. The psychophysics of taste. Am J Clin Nutr. 1978;31(6):1068-1077.

https://doi.org/10.1093/ajcn/31.6.1068

5. Wasalathanthri S, Hettiarachchi $P$ and Prathapan S. Sweet taste sensitivity in pre-diabetics, diabetics and normoglycemic controls: A comparative cross-sectional study. BMC Endocr Disord. 2014;14(1):67. https://doi.org/10.1186/1472-6823-14-67

6. Yu JH, Shin MS, Kim DJ, Lee JR, Yoon SY, Kim SG, et al. Enhanced carbohydrate craving in patients with poorly controlled Type 2 diabetes mellitus. Diabet Med. 2013;30(9):1080-1086 https://doi.org/10.1111/dme.12209

7. Green E and Murphy C. Altered processing of sweet taste in the brain of diet soda drinkers. Physiol Behav. 2012;107(4):560-567. https://doi.org/10.1016/j.physbeh.2012.05.006

8. Feeney E, Leacy L, O’Kelly M, Leacy N, Phelan A, Crowley L, 
et al. Sweet and umami taste perception differs with habitual exercise in Males. Nutrients. 2019;11(1):155.

https://doi.org/10.3390/nu11010155

9. Umabiki M, Tsuzaki K, Kotani K, Nagai N, Sano Y, Matsuoka Y, et al. The improvement of sweet taste sensitivity with decrease in serum leptin levels during weight loss in obese females. Tohoku J Exp Med. 2010;220(4):267-271.

https://doi.org/10.1620/tjem.220.267

10. Pan B, Ge L, Xun Y, Chen Y, Gao C, Han X, et al. Exercise training modalities in patients with type 2 diabetes mellitus: A systematic review and network meta-analysis. Int J Behav Nutr Phys Act. 2018;15(1):72.

https://doi.org/10.1186/s12966-018-0703-3

11. Gauthier AC, de Fátima Guimarães R, Namiranian K, Drapeau V and Mathieu ME. Effect of physical exercise on taste perceptions: A systematic review. Nutrients. 2020;12(9):2741.

https://doi.org/10.3390/nu12092741

12. Kampov-Polevoy AB. Sweet liking and family history of alcoholism in hospitalized alcoholic and non-alcoholic patients. Alcohol Alcohol. 2001;36(2):165-170.

https://doi.org/10.1093/alcalc/36.2.165

13. American College of Sports Medicine. ACSM's HealthRelated Physical Fitness Assessment Manual. Philadelphia, Pennsylvania, United States: Lippincott Williams \& Wilkins; 2013. p. 191.

14. Green BG, Dalton P, Cowart B, Shaffer G, Rankin K and Higgins J. Evaluating the 'labeled magnitude scale' for measuring sensations of taste and smell. Chem Senses. 1996;21(3):323-334. https://doi.org/10.1093/chemse/21.3.323

15. Lim J, Urban L and Green BG. Measures of individual differences in taste and creaminess perception. Chem Senses. 2008;33(6):493-501.

https://doi.org/10.1093/chemse/bjn016

16. Mennella JA, Lukasewycz LD, Griffith JW and Beauchamp GK. Evaluation of the monell forced-choice, paired-comparison tracking procedure for determining sweet taste preferences across the lifespan. Chem Senses. 2011;36(4):345-355.

https://doi.org/10.1093/chemse/bjq134

17. Pathirathna ML, Sekijima K, Sadakata M, Fujiwara N,
Muramatsu $\mathrm{Y}$ and Wimalasiri KM. Impact of second trimester maternal dietary intake on gestational weight gain and neonatal birth weight. Nutrients. 2017;9(6):627.

https://doi.org/10.3390/nu9060627

18. Lee SS, Yoo JH and So YS. Effect of the low-versus highintensity exercise training on endoplasmic reticulum stress and GLP-1 in adolescents with Type 2 diabetes mellitus. J Phys Ther Sci. 2015;27(10):3063-3068. https://doi.org/10.1589/jpts.27.3063

19. Martin B, Dotson CD, Shin YK, Ji S, Drucker DJ, Maudsley S, et al. Modulation of taste sensitivity by GLP-1 signaling in taste buds. Ann NY Acad Sci. 2009;1170(1):98-101. https://doi.org/10.1111/j.1471-4159.2008.05397.x

20. Crystal S, Frye CA and Kanarek RB. Taste preferences and sensory perceptions in female varsity swimmers. Appetite. 1995;24(1):25-36. https://doi.org/10.1016/S0195-6663(95)80003-4

21. Koehler K, Beckford S and Stevens J. High amounts of exercise are associated with an increased preference for high-fat vs. lowfat food choices. FASEB J. 2017;31(S1):Ib372-lb372. https://doi.org/10.1096/fasebj.31.1_supplement.lb372

22. Cattaneo C, Riso P, Laureati M, Gargari G and Pagliarini E. Exploring associations between interindividual differences in taste perception, oral microbiota composition, and reported food intake. Nutrients. 2019;11(5):1167. https://doi.org/10.3390/nu11051167

23. Low J, Lacy K, McBride R and Keast R. The association between sweet taste function, anthropometry, and dietary intake in adults. Nutrients. 2016;8(4):241. https://doi.org/10.3390/nu8040241

24. Jayasinghe S, Kruger R, Walsh D, Cao G, Rivers S, Richter M, et al. Is sweet taste perception associated with sweet food liking and intake? Nutrients. 2017;9(7):750. https://doi.org/10.3390/nu9070750

25. Lim AJ, Teo PS, Tan VW and Forde CG. Associations between psycho-hedonic responses to sweet and savoury tastes with diet and body composition in a sample of Asian females. Foods. 2020;9(9):1318.

https://doi.org/10.3390/foods9091318

\section{Authors Contribution:}

DV- Data collection, data entering, analysis, interpretation of results and preparation of the first draft of the manuscript; SW, PH- Concept and design of the study, interpretation of results, revision of the manuscript

Work attributed to:

University of Sri Jayewardenepura, Nugegoda, Sri Lanka

\section{ORCID ID:}

Ms. Dinithi Vidanage - (1) https://orcid.org/0000-0002-0837-7270

Prof. Sudharshani Wasalathanthri - (D) https://orcid.org/0000-0002-6387-3509

Prof. Priyadarshika Hettiarachchi - (1) https://orcid.org/0000-0001-9312-3138

Source of Funding: Research Grant, University of Sri Jayewardenepura, (ASP/01/RE/MED/2017/31), Conflicts of Interest: None. 